$\begin{array}{ll} & \text { Etnográfica } \\ \text { etnográfica } & \text { Revista do Centro em Rede de Investigação em }\end{array}$

Antropologia

vol. $14(2) \mid 2010$

Vol. $14(2)$

\title{
Daniel Melo e Eduardo Caetano da Silva (orgs.), Construção da Nação e Associativismo na Emigração Portuguesa
}

\section{Eduardo Araújo}

\section{OpenEdition}

\section{Journals}

\section{Edição electrónica}

URL: https://journals.openedition.org/etnografica/346

DOI: 10.4000/etnografica.346

ISSN: 2182-2891

\section{Editora}

Centro em Rede de Investigação em Antropologia

\section{Edição impressa}

Data de publição: 1 junho 2010

Paginação: 407-414

ISSN: 0873-6561

\section{Refêrencia eletrónica}

Eduardo Araújo, «Daniel Melo e Eduardo Caetano da Silva (orgs.), Construção da Nação e

Associativismo na Emigração Portuguesa», Etnográfica [Online], vol. 14 (2) | 2010, posto online no dia 20 julho 2012, consultado o 11 fevereiro 2022. URL: http://journals.openedition.org/etnografica/346 ; DOI: https://doi.org/10.4000/etnografica.346

Este documento foi criado de forma automática no dia 11 fevereiro 2022.

\section{(c) (†) 8}

Etnográfica is licensed under a Creative Commons Attribution-NonCommercial 4.0 International License. 


\title{
Daniel Melo e Eduardo Caetano da Silva (orgs.), Construção da Nação e Associativismo na Emigração Portuguesa
}

\author{
Eduardo Araújo
}

\section{REFERÊNCIA}

Daniel Melo e Eduardo Caetano da Silva (orgs.), Construção da Nação e Associativismo na Emigração Portuguesa, Lisboa, Imprensa de Ciências Sociais, 304 páginas.

1 Construção da Nação e Associativismo na Emigração Portuguesa surge aos nossos olhos, antes da leitura dos conteúdos e com apenas o que o título nos sugere em mente, como uma obra muito positiva em pelo menos dois aspectos: é publicada num momento de retoma da emigração portuguesa e na senda de uma série de anos de relativa invisibilidade do tema na produção científica nacional; os temas abordados (o associativismo português na emigração e as dinâmicas do nacionalismo português nesse contexto) são temas insuficientemente trabalhados no panorama das ciências sociais em Portugal. Coligir uma série de trabalhos em torno desses temas e organizar este volume configura-se então como uma importante contribuição para o aprofundamento dos conhecimentos existentes sobre as "comunidades portuguesas" e seus processos de criação, manutenção, afirmação ou integração. Daniel Melo (historiador, tem trabalhado sobre associativismo voluntário, nacionalismo e migrações) e Eduardo Caetano da Silva (antropólogo, a finalizar o doutoramento com um estudo sobre migrantes portugueses em São Paulo) são quem organiza as contribuições de autores de diversas áreas das ciências sociais (da antropologia à história, à sociologia e à ciência política) que têm trabalhado em diferentes contextos da emigração portuguesa. 
2 Na introdução assinada pelos organizadores é explicado ao leitor o âmbito do livro: "É [...] [na] organização de redes associativas entre os portugueses vivendo fora de Portugal que os trabalhos apresentados neste livro encontram um ponto de partida e um pretexto para tratar da problemática da migração face à questão nacional." (pp. 22-23) O livro propõe-se então "estimular o debate acerca das relações que se estabelecem entre a emigração e as reconfigurações do nacionalismo português e o papel desempenhado por associações de emigrantes nesse contexto" (p. 23). Também assinado por Daniel Melo e Eduardo Caetano da Silva é o capítulo 1, que, intitulado "Associativismo, emigração e nação: o caso português", é mais introdutório às questões propostas do que a própria introdução. É, nesse sentido, o capítulo central da obra, e um artigo muito importante no contexto dos temas referidos, porque busca oferecer um panorama dos variados cenários da emigração portuguesa e do associativismo migrante português. Através de um levantamento bibliográfico relativamente extenso, é apresentada a análise dos temas propostos feita pelos organizadores, criando uma moldura na qual se pode inserir o quadro composto pelas contribuições dos restantes autores. Começando por dar conta das diferentes posições que o Estado português tem assumido nas últimas décadas em relação à emigração nacional, o texto passa depois para a questão das identidades migrantes e a importância do fenómeno associativo na emigração portuguesa. Este, segundo os autores,

[...] é chamado a assumir um papel destacado, e a tomar a dianteira no movimento de perpetuação da identidade e da cultura portuguesas para as futuras gerações, buscando atrair novos participantes, disseminar a língua e a cultura portuguesas e despertar o interesse pelas raízes portuguesas. Todavia, o significado dessas raízes, da língua, da cultura e, enfim, da própria identidade portuguesa, não é consensual, antes expondo os conflitos que a ideia de nação costuma ocultar ou dissolver na naturalização do trinómio povo-território--cultura. (p. 41)

3 Este primeiro capítulo permite ao leitor encetar a leitura do livro com uma reflexão, que depois acaba por ser transversal a toda a obra, e por lançar questões presentes em todos os restantes capítulos:

Como os emigrantes são, se tornam ou deixam de ser portugueses? Como é ser português em França, no Brasil, na Bélgica, etc.? Que tipo de capital simbólico representa a portugalidade em diferentes cenários da emigração? Quais os sentidos de conceber a emigração como um conjunto de comunidades portuguesas ou como uma diáspora uniforme e indistinta? (p. 60)

4 Constituindo um "espaço de difusão do sentido de pertença nacional precarizado pela distância face ao território de origem", o associativismo migrante e os emigrantes sãonos então desenhados pelos autores como um marcador (tanto deliberado como involuntário) da "presença de Portugal nos países onde residem, e oferecem novos significados à ideia de um 'modo português de estar no mundo"” (p. 61).

Este estado da arte do tema "associativismo, emigração e nação" abre então caminho para os capítulos seguintes. João Leal (antropólogo) leva-nos no capítulo 2 até Nova Inglaterra, onde analisa as organizações açoriano-americanas no contexto da realização das Grandes Festas do Espírito Santo e, no plano teórico, o transnacionalismo enquanto eixo estruturante da vida da comunidade portuguesa ali. Circunscrevendo o transnacionalismo a ocupações e actividades que requerem contactos sociais transfronteiriços regulares e sustentados ao longo do tempo, Leal demarca-se das posições teóricas mais maximalistas que tendem a associar automaticamente o transnacionalismo à imigração, e procura neste texto averiguar o estatuto de três 
modalidades específicas de transnacionalismo (a saber, político, sociocultural, e envolvimento transnacional dos activistas). Assim, Leal explora a importância das Grandes Festas na manutenção de uma identidade açoriano-americana e de que formas as práticas transnacionais (nessas três modalidades) se revelam ou não preponderantes, sublinhando: "O estatuto de transnacionalidade na comunidade açoriano-americana pode justamente ser visto como uma expressão da diversidade da comunidade. Nela existem transnacionais e transnacionalidade, mas distribuídos de forma desigual, com áreas de maior e menor intensidade." (p. 93) No capítulo 3 viajamos até ao Uruguai, na companhia de Helena Carreiras (socióloga) e Andrés Malamud (politólogo). Em "Associações portuguesas, integração social e identidades colectivas", os autores questionam "de que forma o associativismo presente dos imigrantes portugueses e lusodescendentes ostenta marcas do que foi, e é, o seu processo de integração social", bem como em "que medida participa em processos de etnicização e/ou de assimiliação", e "Que objectivos cumprem as associações no jogo de construção identitária [...] [nesses] grupos e indivíduos." (p. 98) "A mesma juventude noutra latitude: lusodescendentes do Brasil e da França frente ao projecto nacional das comunidades portuguesas" é o título do quarto capítulo, da autoria de dois antropólogos, Eduardo Caetano da Silva e Inês Strijdhorst dos Santos. Este texto tem como objecto central a lusodescendência. Nas palavras dos autores, enquanto a categoria "emigrantes" "ao pouco se perenizou como uma categoria cujo sentido forte remete ao 'ter saído' ou ao 'estar fora', o lusodescendente, necessariamente um indivíduo 'de fora', é definido nos discursos oficiais como legítima extensão da nação" (p. 171). Mostrando-nos como o Estado português abraçou essa ideia, e dando-nos conta dos traços gerais do contexto associativo e da lusodescendência no Brasil (São Paulo) e em França (Paris), os autores reflectem sobre o encontro mundial de lusodescendentes realizado em Portugal, em 2001. A história de vida de um emigrante português em França é o mote para o texto do capítulo 5, de Elsa Lechner (antropóloga), onde são explorados os trilhos de múltiplas formas de construção da portugalidade, em diversos contextos e para diferentes públicos. No sexto capítulo, Daniel Melo (historiador) leva-nos a explorar o movimento associativo português na Bélgica, apresentando não apenas uma série de dados quantitativos sobre este, mas também uma análise sobre a evolução do movimento nas últimas décadas e as relações com o Estado português (e vice-versa). O penúltimo capítulo, o sétimo, é da autoria de Andrea Klimt (antropóloga), e são analisadas nesse texto as noções de "casa" e "pertença" dos emigrantes portugueses na Alemanha nas últimas décadas (mais propriamente desde a década de 1980). São aí analisadas as razões que levaram grande parte da emigração portuguesa para a Alemanha a passar de temporária a de longo prazo, sendo inseridos nessa análise os debates sobre a participação da comunidade na sociedade alemã pós-reunificação e o facto de os portugueses adquirirem a cidadania europeia a partir do tratado de Schengen, em 1992. Chamando a atenção em vários momentos para o cariz transnacional que muitas das vidas migrantes na Alemanha adquiriram ao longo das últimas décadas, a autora afirma que estes "experimentaram de forma criativa organizar as suas vidas, famílias e comunidades, mais através do que no interior dos espaços nacionais" (p. 268). A fechar este volume temos a contribuição de Toffoli da Silva (antropólogo), "Entre vítimas e algozes: dilemas da 'comunidade portuguesa' na África do Sul pós-apartheid", onde nos é dada a ler uma análise etnográfica de um "processo de disputa pela representação da comunidade portuguesa residente em Johanesburgo" (p. 273), chamando-nos a atenção 
para o "papel central que o debate público sul-africano exerce na definição das possibilidades de identificação colectiva" (p. 298).

6 Sumarizando, este volume oferece ao leitor uma série de diferentes experiências e reflexões que têm como centro temático o associativismo migrante e os processos de construção da nação na emigração portuguesa. Os diferentes insights sobre as políticas da identidade de grupos de migrantes põem à mostra a importância dos contextos de acolhimento, os papéis do Estado de partida nesses processos, e como as gerações de descendentes de migrantes lidam com essas realidades. Ao mesmo tempo que são apresentados dados etnográficos sobre movimentos associativos de diversos contextos migratórios, são apresentados também "os nexos entre experiência migratória e as dinâmicas do nacionalismo português”.

7 Se a emigração no geral tem sofrido de uma relativa invisibilidade na academia, maior ainda tem sido a falta de estudos sobre a experiência dos migrantes nos seus destinos migratórios e sobre o associativismo migrante e o seu papel nos processos de auto e heteroconstrução das comunidades de pertença, pelo que este livro encontra uma boa parte do seu valor no facto de vir ajudar a preencher essas lacunas.

\section{AUTORES}

EDUARDO ARAÚJO

CRIA/FCSH-UNL 